Article

\title{
Making Sustainable Consumption and Production the Core of Sustainable Development Goals
}

\section{Lewis Akenji * and Magnus Bengtsson}

Institute for Global Environmental Strategies, 2108-11 Kamiyamaguchi, Hayama, Kanagawa 240-0115, Japan; E-Mail: bengtsson@iges.or.jp

* Author to whom correspondence should be addressed; E-Mail: akenji@iges.or.jp; Tel.: +81-46-826-9594; Fax: +81-46-855-3709.

Received: 29 November 2013; in revised form: 15 January 2014 / Accepted: 16 January 2014 / Published: 24 January 2014

Abstract: This paper argues that sustainable consumption and production (SCP) should play a prominent role in the formulation and implementation of the sustainable development goals (SDGs) and discusses how this could be practically done. Unsustainable patterns of consumption and production have been declared the primary cause of environmental deterioration. This was clearly recognized already at the United Nations Conference on Environment and Development (or the Rio Summit) in 1992; and this recognition has been reconfirmed in all high-level sustainability meetings since then. SCP aims to change these patterns; it is a policy agenda for addressing the root causes of our ecological predicament, while, at the same time, providing for human wellbeing and prosperity. Drawing from international agreements, practical policy experience and research from a range of disciplines, the paper provides a clarifying framework for scientifically robust, policy-relevant and practical goal-setting for SCP within the SDGs. Special attention is given to how SCP in the SDGs can create synergies with other international policy initiatives. The paper explores the advantages and disadvantages of two possible options for reflecting SCP in the SDGs framework: (i) SCP as a stand-alone goal; and (ii) SCP as a cross-cutting objective, embedded within relevant goals. While these two options are not necessarily mutually exclusive, given the competing number of issues for prioritization and the fact that a 10-Year Framework of Programs on SCP has also recently been established, it is hardly foreseeable that both options can be realized. The paper further proposes a set of basic principles for SCP at the global level and makes recommendations towards the formulation of indicators supporting SCP objectives in the SDGs. 
Keywords: sustainable consumption and production; sustainable development goals; sustainability policy; wellbeing; goal-setting

\section{Introduction: SCP and International Mandates}

In 1992 at the Rio Earth Summit, world leaders acknowledged that "the major cause of the continued deterioration of the global environment is the unsustainable pattern of consumption and production" [1]. This central role of sustainable consumption and production (SCP) towards sustainable development (SD) was reaffirmed at the World Summit for Sustainable Development in 2002; SCP was declared once again one of the "overarching objectives of, and essential requirements for, sustainable development" [2]; the other two objectives are environmental protection and poverty reduction. At the recent Rio+20 conference, leaders adopted a global 10-Year Framework of Programs (10YFP) to enhance international cooperation and to support concrete regional and national initiatives towards SCP in both developed and developing countries. The UN Environment Program (UNEP), serving as secretariat, is preparing to launch several programs under the 10YFP. As evidenced by these developments, SCP has had a consistently strong recognition at the highest international political level for over two decades and has been embedded at the core of achieving SD. In the formulation of sustainable development goals (SDGs), as mandated in the agreement from Rio+20 [3], SCP should therefore be placed as a high priority.

This is especially the case as the SDGs and the follow-up to the Millennium Development Goals (MDGs) will likely be brought under the same framework as the Post-2015 Development Agenda [4]. In setting the MDGs, most environmental issues were lumped together under MDG 7: to ensure environmental sustainability. It was then assigned targets relating to environmental resources, biodiversity, water and sanitation and poverty. Attaining the MDGs requires the production and consumption of more goods and services to meet the basic needs and aspirations of the poor, while keeping within planetary limits; this latter part is, however, poorly articulated in the existing MDGs. In assessing lessons learnt from the MDGs, the Report of the High-Level Panel of Eminent Persons on the Post-2015 Development Agenda sees a missed opportunity: "Most seriously, the MDGs fell short by not addressing the need to promote sustainable patterns of consumption and production" [4]. The Panel then asks for "a rapid shift" to SCP.

As part of consultations on the SDGs, in October 2012, the United Nations Department of Economic and Social Affairs (UNDESA) provided a questionnaire to national governments with one of the questions focusing on thematic areas that countries considered priorities for SDGs. The responses from countries were then ranked according to the frequency of occurrence. The ten top thematic priorities for national governments were: sustainable energy; food security; water and sanitation; biodiversity protection; desertification/land degradation; sustainable consumption and production; oceans and marine systems; poverty eradication; gender equality; and education [5]. This is just one of many lists of possible goals that has been developed; however, this one is authoritative and indicative of the priorities of governments, the stakeholders that will be leading 
actors in the design and implementation of the SDGs. SCP and its key related issues repeatedly appear among most sets of goals that have so far been published.

In terms of approaches, the High-Level Panel sees SCP at the core of SD; "not directly addressed through a single goal", but as a cross-cutting issue to be embedded within other goals [4]. The Sustainable Development Solutions Network (SDSN) emphasizes the importance of SCP and chooses to reflect this by placing "a central emphasis on decoupling living standards and economic growth from unsustainable resource use and pollution" and then more specifically highlighting it under Goal 2: achieve development within planetary boundaries. Further illustrating the importance accorded the concept, the SDSN sees a need to provide a justification in the form of a question-and-answer: "Why is there no proposed goal called 'Sustainable Consumption and Production'?” [6]. The Open Working Group on SDGs highlights SCP as a "crucial topic" [7], and the survey by UNDESA shows that several countries and stakeholders have highlighted the need for SCP in the SDGs. Our conclusion from this brief overview is that there seems to be a broad agreement among key stakeholders that SCP should be reflected in the SDGs, perhaps even playing a central role in this global framework. However, how it should be included remains an open question. In the rest of the paper, we discuss two main options for how SCP can be reflected and highlight some critical aspects that negotiators should bear in mind.

\section{Options for Including SCP in SDGs}

Unpacking the concept of SCP reveals a broad range that touches upon almost all socio-economic activities and their impact on the environment, from deep sea trawling for fish to meditation in a mountain hut. The UN Environment Program (UNEP) uses this cumbersome, but technically descriptive, definition of SCP: "The use of services and related products which respond to basic needs and bring better quality of life while minimizing the use of natural resources and toxic materials as well as the emissions of waste and pollutants over the life cycle of the service or product so as not to jeopardize the needs of future generations" [8].

The approach to "decouple" economic growth from resource use and environmental degradation has often been promoted as one of the key means of achieving SCP [6,9]. Critics, however, have stressed that decoupling is ineffective for dealing with the challenges presented by the project of sustainability [10]. Indeed, after more than two decades of international policy discussions on sustainability (or four decades if one considers the 1972 Stockholm conference as the starting point), there have been only a few examples of countries achieving relative decoupling (where material consumption and associated environmental pressure grow at less rapid rates than the economies) and no example of absolute decoupling, the measure needed to achieve sustainability. The decoupling approach thus remains largely theoretical, based on questionable assumptions, for example, of rapid technological progress with limited undesirable side-effects in the form of rebound effects. Despite its widespread use in discussions on SCP, there is almost no empirical evidence, and little theoretical justification, that decoupling could actually work in practice at the global scale.

One of the flaws of decoupling as the main approach to SCP is that it gives primacy to the economic dimension of sustainability. It is based on the assumption that economic growth can and should continue, seemingly ad infinitum, and it does, therefore, in practice, assign a secondary role to 
other sustainability objectives. It is politically appealing, since it denies the possibility of trade-offs between different objectives. Recent scientific recommendations have highlighted the need to shift beyond the technological fixes that have characterized many SCP initiatives to date and to examine and address the systemic factors that drive continuously growing production and consumption [11]. As such, in order to effectively accelerate a shift to SCP, the SDGs would have to go beyond the green consumerism that has characterized many SCP initiatives to date [12]. SDGs, associated indicators and implementation arrangements should be developed to address the social and cultural aspects that facilitate and constrain production and consumption patterns.

Already, Agenda 21 recognized the need for a broad approach to achieving SCP. In Chapter 4, titled "Changing Consumption Patterns", it calls for "new systems of national accounts and other indicators of sustainable development" that do not depend on economic growth. Rather, there should be "new concepts of wealth and prosperity which allow higher standards of living through changed lifestyles and are less dependent on the Earth's finite resources and more in harmony with the Earth's carrying capacity" [1]. This perspective on SCP should serve as a frame for the SDGs, providing a fitting preamble to and aspiration for them, in keeping with SCP as an "overarching objective" of SD.

SCP can thus be defined as having two broad and interrelated objectives:

(1) The achievement of wellbeing for all people; and

(2) Keeping the negative environmental impacts of socio-economic activities to within carrying capacity.

SCP has been mentioned as being broad in scope. Chapter 4 of Agenda 21 starts by acknowledging that "Since the issue of changing consumption patterns is very broad, it is addressed in several parts of Agenda 21, notably those dealing with energy, transportation and wastes" [1]. As can be seen in the UNDESA list of top country priorities mentioned above, almost all the thematic areas have strong linkages to production and consumption. In other words, the patterns of consumption and production determine the degree of sustainability of the highlighted thematic areas: energy production is related to $\mathrm{CO}_{2}$ emissions; agricultural practices are linked to food security; industrial pollution affects water quality; biodiversity loss is linked with land use patterns; marine issues are linked with over-fishing and acidification from $\mathrm{CO}_{2}$; wood production and mining could lead to desertification and land degradation; gender equality and education are linked to access to resources and better quality of life. SCP highlights both the complexity and interlinkages among sustainability issues. It is reflected as a cross-cutting theme in several multilateral environment agreements (MEAs) and is often highlighted in sustainability initiatives for a broad range of sectors and issues (see Table 1). It is for this reason that SCP becomes both an easily identifiable priority and, yet, a complex objective to integrate in the SDGs. 
Table 1. sustainable consumption and production (SCP) is reflected in several multilateral environment agreements (MEAs) and high-profile sustainability initiatives.

\begin{tabular}{|c|c|c|}
\hline $\begin{array}{c}\text { Main } \\
\text { sustainability } \\
\text { theme } \\
\end{array}$ & $\begin{array}{l}\text { Initiative or } \\
\text { MEA }\end{array}$ & Related SCP objective, goal or target \\
\hline Food security & $\begin{array}{l}\text { Zero Hunger } \\
\text { Challenge }\end{array}$ & $\begin{array}{l}\text { Achieve } 100 \text { percent access to adequate food all year round; } \\
\text { end malnutrition in pregnancy and early childhood; } \\
\text { make all food systems sustainable; } \\
\text { increase growth in the productivity and income of smallholders, } \\
\text { particularly women; } \\
\text { achieve a zero rate of food waste. }\end{array}$ \\
\hline Energy & $\begin{array}{l}\text { Sustainable } \\
\text { Energy for All } \\
\text { Initiative (SE4All) }\end{array}$ & $\begin{array}{l}\text { Goal of achieving sustainable energy for all by 2030, including: } \\
\text { energy access; } \\
\text { renewable energy; and } \\
\text { energy efficiency. }\end{array}$ \\
\hline Biodiversity & $\begin{array}{l}\text { Strategic Plan for } \\
\text { Biodiversity } \\
\text { 2011-2020, under } \\
\text { Convention for } \\
\text { Biodiversity }\end{array}$ & $\begin{array}{l}\text { Aichi Biodiversity Targets require that "by } 2020 \text {, at the latest, } \\
\text { Governments, business and stakeholders at all levels have taken steps to } \\
\text { achieve or have implemented plans for sustainable production and } \\
\text { consumption and have kept the impacts of the use of natural resources } \\
\text { well within safe ecological limits." (Conference of the Parties (COP) } 10 \\
\text { Decision X/2 Strategic Plan for Biodiversity 2011-2020). }\end{array}$ \\
\hline $\begin{array}{l}\text { Hazardous } \\
\text { Waste }\end{array}$ & $\begin{array}{l}\text { The Basel } \\
\text { Convention on the } \\
\text { Control of } \\
\text { Transboundary } \\
\text { Movement of } \\
\text { Hazardous Wastes } \\
\text { and their Disposal }\end{array}$ & $\begin{array}{l}\text { Seeks to address issues arising from the generation and disposal of } \\
\text { dangerous wastes resulting from production and consumption practices. } \\
\text { It takes a life-cycle approach and places restrictions on movements of } \\
\text { hazardous wastes from developed to developing countries. } \\
\text { It also has a partnership program that has encouraged SCP in several } \\
\text { sectors, e.g., establishing guidelines on the sound management of } \\
\text { end-of-life mobile phones and computing equipment. }\end{array}$ \\
\hline
\end{tabular}

States that policies and programs for the sustainable conservation and management of forests should take into account "all aspects related to the production, consumption, recycling and/or final disposal" of forest The Forest products. It includes explicit recommendations for countries to Forestry Principles undertake environmental impact assessments and adopt national forestry action plans. In 2001, 14 international organizations formed the Collaborative Partnership on Forests, with a mission to promote the sustainable management of forests, including the Food and Agricultural Organization, World Bank and The UN Environment Program (UNEP). Source: UNEP [13]; UNTST [14].

Based on previous international sustainability strategies and goals (for example, Agenda 21, MDGs, Montreal Protocol, several national SD strategies and action plans), the SDG Open Working Group outcomes and reports [4,7], so far , as well as on expert recommendations $[15,16]$, that the SDGs would likely be structured in the following manner:

- Overall vision and objectives to guide implementation;

- A limited number (probably not more than ten) of integrated main goals (we use the word "stand-alone" goals in this paper, to be more descriptive); 
- A set of subsidiary goals under each of the integrated goals;

- Targets and indicators for each goal or subsidiary goal;

- A monitoring framework for tracking progress during implementation.

Figure 1. A framework for sustainable development goals (SDGs).

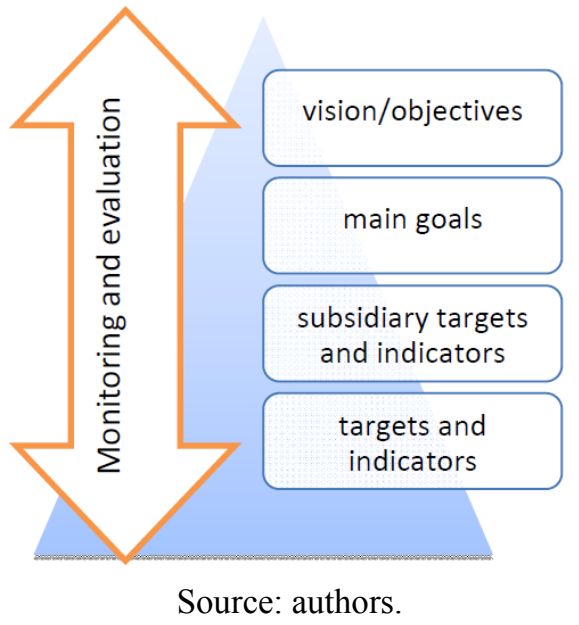

An effective framing of SCP in the context of the SDGs, with associated indicators and implementation arrangements, would require:

(1) A thorough understanding of the drivers of production and consumption, including the social, economic and cultural context in which these activities take place (e.g., inequity, commodification of culture and many forms of human interaction, individualism and competition, marketing and advertising practices, corporate governance and the design of financial markets);

(2) Understanding patterns of production and consumption in society (planned obsolescence in products, inefficiencies, peer-to-peer influence), including how they respond to the identified drivers; and

(3) Using a lifecycle perspective, prioritizing areas where production and consumption have the highest impact on society and the environment (food and agriculture, transport and mobility, housing and construction and manufactured goods)

The above would be used in setting an SCP goal and/or subsidiary goals, indicators and concrete targets to support the SCP objective of achieving wellbeing within the ecological limits of the planet. This is examined in the following sections, with two main options discussed. The first option is to make SCP a stand-alone goal, one of the main goals of the SDGs. The second option is to break it down into its various practical key issues and then, as a cross-cutting SC objective, embed it as subsidiary goals and indicators across the main goals. The practicalities of each of these options are discussed, as well as their advantages and disadvantages. However, the tendency to recommend one "better" option is resisted. The intention of this paper is to provide a clarifying framework for scientifically robust, policy relevant and practical goal-setting for SCP within the SDGs. Furthermore, as SCP is already officially designated by UN member states as an overarching objective of SD [2], it 
is expected to be included among the broader objectives of the SDGs. Thus, this option is not discussed here in further detail.

\subsection{SCP As a Stand-Alone Goal}

As a stand-alone goal, SCP would be highlighted as a top priority for international and national policy and action. In addition to being a policy goal, it would be clearly recognizable to individual citizens and consumers, thus contributing to easier communication. With the overall objective of achieving wellbeing for all while minimizing negative impacts on the environment, the goal will then be broken down to a set of subsidiary goals, each with clear targets and concrete, measurable indicators.

There are both advantages and disadvantages to having SCP as a stand-alone goal. If the goals are meant to integrate all the dimensions of sustainability, SCP is a strong vehicle for such integration. It brings together economic elements of production and consumption, social aspects driven by and resulting from production and consumption patterns and environmental impacts from across product lifecycles. Such an inherently integrative nature of SCP means that subsidiary goals and targets cannot be effectively dealt with in silos and would require a more systemic approach.

Another major advantage of SCP as a stand-alone goal is that it would immediately focus the political attention of all stakeholders and demand action at local, national and international levels. It would mean, for example, bringing attention to sustainability issues from consumption and production patterns in the current growth-oriented economic system, the often misrepresented lack of clear correlation between continuous economic growth and wellbeing [17], and the extent to which small "green" individual consumer actions at the fringes of economic activity fail to address the urgency and scope of the complex unsustainability of the economic system [12]. Issues of health, equity and livelihoods would take center stage on the social sustainability side. The effects of production and consumption on the environment would also become focal points. Resource extraction and the associated social and environmental consequences, land use and biodiversity loss, industrial pollution and effects on water, air and soil quality, issues, which have long been skirted because of political expediency, would rightfully have to be addressed. Actions on these issues would also be backed by resources mandated under the Post-2015 Development Agenda, which will affect development aid flows and spending priorities.

Shifting to SCP involves complex systemic issues. For SCP to be practically implementable as a goal would require nothing short of a critical review of the culture of consumerism that has become pervasive through mass media and advertisements, has been internalized by billions of consumers around the world and which has come to define modern macro-economic thinking and the existing economic system. The SDG mandate from Rio+20 [3] asks for a set of clearly defined goals on priority issues; SCP is notably broad, and there is no clear definition of its boundaries. Placing SCP as a standalone goal would mean it partly overlaps and competes with all or most other SDGs. It would require that most other areas-energy, food, health, etc., which are related with the production and consumption of goods and services - be addressed both under the SCP goal and as separate stand-alone goals. This then presents a further challenge of how to design the other main goals, if they are already addressed under SCP. Perhaps, the question here is less about the nature of the concept of 
SCP and its suitability as a main goal, but the strength of the mandate for the Post-2015 Development Agenda and its ability to accomplish truly ambitious SDGs.

As regards the advantage of giving higher visibility, in a sense, the 10-Year Framework of Programs for sustainable consumption and production (10YFP) already raises the profile of SCP. The 10YFP was adopted at the same Rio+20 meeting, which gave the mandate for the SDGs. Accordingly, over the next 10 years, a set of programs will be developed to support implementation activities at national and regional levels with the objective of changing production and consumption patterns. With an SCP 10YFP and an SCP SDG, there will be overlap in the issues addressed and the periods of implementation. If SCP is placed as a stand-alone SDG, it should complement, rather than compete, with the 10YFP. However, this would require good coordination; care should be taken to prevent an unproductive turf war and fight over limited resources and policy attention by different parts of the UN system. A question arises, however, about whether, with limited resources dedicated to sustainability issues, it is realistic to expect that one theme, SCP, despite its acknowledged importance, would be accorded such political space and the necessary resources provided to support implementation.

Box 1. Basic criteria of the 10-Year Framework of Programs (10YFP).

- Contribute to meeting the goals and principles of the 10-Year Framework of Program, as well as to the three pillars of sustainable development;

- Respond to national and regional needs, priorities and circumstances;

- Be based on lifecycle approaches, including resource efficiency and sustainable use of resources, and related methodologies, including science-based and traditional knowledge-based approaches, cradle-to-cradle and the 3R concept, as appropriate;

- Be based on a solid scientific and policy knowledge base;

- Be consistent with international obligations;

- Encourage the involvement of all relevant stakeholders;

- Consider the use of a mix of efficient instruments, such as education, training and data collection, as well as research activities in each program, as appropriate;

- Promote synergies with work in similar areas, in order to leverage resources towards mutual objectives, and minimize the duplication of ongoing efforts, including in other international forums.

Source: UNEP [18].

There is the risk that divided attention between SCP under the SDGs and SCP under the 10YFP would thin down the potential results. Negotiations and previously agreed goals on addressing climate change as an independent MEA have shown how agreements on pressing issues do not necessarily always arrive at good results; in this case, the climate change problem has instead gotten worse during the period of implementation of the Kyoto Protocol.

For SCP to be a stand-alone goal, there needs to be an assessment of the differences between the mandate for the SDGs and the 10YFP and for the SCP SDG to the address areas that the 10YFP does not cover. However, the 10YFP is a flexible framework that is only gradually taking shape. The initial five indicative programs are: consumer information; sustainable lifestyles and education; sustainable public procurement; sustainable buildings and construction; and sustainable tourism, including 
ecotourism. Both member states and experts have signaled that the initial list of programs is not comprehensive enough and fails to capture the more strategic issues and urgent aspects of SCP. The list of programs from Rio +20 , however, is only indicative, and countries and stakeholders have the option of proposing more programs where relevant. Food and agriculture has already been identified as a strong candidate, and the 10YFP could include a program on this topic.

The question then is which approach will be more successful towards realizing the SCP objectives: to strengthen the 10YFP further by requesting more programs and providing it more resources or to demand SCP as a stand-alone SDG. Straddling both could drop SCP between the cracks of policy debate.

Table 2. Advantages and disadvantages of SCP as a stand-alone SDG.

\begin{tabular}{ll}
\hline Advantages & Disadvantages \\
\hline $\begin{array}{l}\text { Puts a pointed focus on SCP as a core objective } \\
\text { of SD and an area for action. }\end{array}$ & $\begin{array}{l}\text { May overlap and compete with other SD goals since SCP, as } \\
\text { an overarching and cross-cutting approach to SD, is a part of } \\
\text { all other sustainability goals. }\end{array}$ \\
\hline $\begin{array}{l}\text { Broadens the number of international high } \\
\text { profile mandates directly addressing SCP, } \\
\text { including development aid. }\end{array}$ & $\begin{array}{l}\text { Requires careful coordination with the 10YFP to avoid } \\
\text { duplication and unproductive competition. }\end{array}$ \\
\hline $\begin{array}{l}\text { Makes it easier to highlight wellbeing as the } \\
\text { primary objective of consumption and } \\
\text { production. }\end{array}$ & $\begin{array}{l}\text { Limitations of precise indicators and lack of data for } \\
\text { measuring concrete targets, especially as regards social } \\
\text { aspects, might make implementation difficult }\end{array}$ \\
\hline & $\begin{array}{l}\text { Could establish SCP as a siloed activity to be dealt with in } \\
\text { isolation from other areas. }\end{array}$ \\
\cline { 2 - 2 } $\begin{array}{l}\text { Makes it easier to communicate SCP to all } \\
\text { stakeholders, including individual consumers } \\
\text { and citizens. }\end{array}$ & $\begin{array}{l}\text { Might be regarded mainly as an environmental goal with } \\
\text { implementation responsibility assigned to government } \\
\text { bodies with limited resources and weak influence in the } \\
\text { policy process. }\end{array}$ \\
\hline
\end{tabular}

\subsection{SCP as a Cross-Cutting Objective Embedded in Other Goals}

This second option places SCP not as a stand-alone goal but embeds it in other relevant goals, in certain cases as subsidiary goals. In this case, the main goals will be defined and, under each, SCP will be broken down into its various practical components (e.g., equity, resource use, waste) and embedded where and as appropriate. Realization of this approach will again have to be through identifying indicators for SCP and then setting concrete targets for each. As such, SCP would be spread across different thematic areas; it could fall under goals such as food and energy security, biodiversity protection, water, etc., serving as a cross-cutting theme of the SDGs.

This is an approach that has already been taken with goals under different multilateral environmental agreements (see Table 1). Phasing out production and consumption of ozone depleting substances is central to the Montreal Protocol; the Aichi Targets adopted by the Convention on Biological Diversity require that by 2020 stakeholders at all levels would have moved towards "sustainable consumption and production and have kept the impacts of use of natural resources well within safe ecological limits"; all eight Millennium Development Goals are in a sense based on SCP tenets, although mainly from the perspective of increasing consumption opportunities for low-income 
segments. Experiences from developing and working to achieve these previous goals could be brought to bear if the cross-cutting option is taken.

As with the stand-alone option, SCP as a cross-cutting goal also presents some advantages and disadvantages. The first advantage of embedding SCP in all other SDGs is that it allows the full breadth of the concept to be potentially explored; the SCP approach can be used to create interlinkages and connect the dots between the inherently complex but ultimately integrated dimensions of SD challenges: climate change, water scarcity, energy shortages, global health, food security, women's empowerment, biodiversity loss, atmospheric pollution, waste generation. This makes SCP the mainstay of SD and in fact brings it around to serving as the "overarching objective" that the 2002 Johannesburg Summit declared it to be.

By the same token, embedding it as a cross-cutting topic runs the risk of causing confusion with SCP perceived as being everywhere and nowhere at the same time. Practically speaking, at the stage of developing the goals and during implementation, without adequate knowledge and dexterity SCP could be spread thin and weakened. It could end up falling between the goals, especially where certain aspects do not fit well under these goals. A critical aspect of this approach lies in the setting of targets and design of indicators. Weak or ambiguous targets that are hard to monitor and indicators dogged by low data availability and poor data quality could hamper implementation. More fundamentally, SCP calls for a paradigm shift and given the current climate of limited political will it might be challenging to embed it in the main goals in such a way that it provides a strong impetus for systemic transformation. Yet these issues dog also the implementation of the 10YFP - the SCP focused global framework for action.

The option to embed SCP provides an opportunity to complement and strengthen the 10YFP. In contrast to a stand-alone SCP goal that might compete with the 10YFP mandate, an integrated cross-cutting approach could identify the thematic areas where the 10YFP falls short and reflect these in the development of indicators and targets for SCP under the SDGs. This would in practice serve as a bridge between the two mandates, where a complementary set of indicators is used for the 10YFP and for SCP components of the SDGs. During implementation, a common monitoring framework could then be developed to track progress towards overall SCP objectives and to report accomplishment (or the lack thereof) of set targets. In this case the 10YFP Secretariat under UNEP would also have a defined role to play in the implementation of the Post-2015 Development Agenda.

Table 3. Advantages and disadvantages of SCP as a cross-cutting SDG.

\begin{tabular}{ll}
\hline Advantages & Disadvantages \\
\hline $\begin{array}{l}\text { Reflects that SCP is a cross-cutting objective rather than a } \\
\text { sectoral issue }\end{array}$ & $\begin{array}{l}\text { SCP is less visible up-front. Some major stakeholders, } \\
\text { including consumers and citizens will not be addressed } \\
\text { directly and will feel less engaged. }\end{array}$ \\
\cline { 1 - 2 } Could generate more resources for SCP implementation & \multirow{2}{\text{Stressesdemand-sidemanagement(settinglimitsto}}{$\begin{array}{l}\text { The full breadth of SCP will not be addressed, since } \\
\text { consumption) in all major areas }\end{array}$} \\
$\begin{array}{ll}\text { Facilitates mainstreaming of SCP by mandating sectoral } \\
\text { agencies to work towards SCP objectives }\end{array}$ & $\begin{array}{l}\text { possible to fit under the main goals. } \\
\text { Easier to achieve complementarity with the 10YFP }\end{array}$ \\
\hline
\end{tabular}




\section{Capturing the Essence of SCP: Basic Principles for the Design of Indicators and Targets}

\subsection{Reflecting the Global Relevance of SCP}

Having analyzed the advantages and disadvantages of presenting SCP in the SDG framework, this section discusses some basic principles that should underpin either approach. The SDGs are supposed to be universal, applying to all countries of the world. In this respect, a challenge to the SCP theme of the SDGs would be to reconcile the differences in quality and quantity of production and consumption between developed and developing countries. Not only have historic levels of consumption by developed economies been high, present rates of consumption remain much higher than in developing economies and above sustainability thresholds. On the other hand, developing economies still need to increase production and consumption in several areas in order to meet basic levels of wellbeing $[19,20]$, and most are presently operating below ecological limits. Figure 2 illustrates this situation, with advanced countries scoring high on the Human Development Index, but clearly exceeding available biocapacity, and developing countries lagging behind on human development, but also, in most cases, consuming less than the available ecological space. SCP therefore means different, sometimes opposite, things to developed and developing countries. For the SDG process, it is a particular challenge to formulate goals, indicators and targets that reflect this reality.

Policy makers have already acknowledged this dichotomy. Agenda 21 declares that "Although consumption patterns are very high in certain parts of the world, the basic consumer needs of a large section of humanity are not being met. This results in excessive demands and unsustainable lifestyles among the richer segments, which place immense stress on the environment. The poorer segments, meanwhile, are unable to meet food, health care, shelter and educational needs" [1].

Figure 2. The uneven distribution among nations of human development (horizontal axis) and ecological footprint (vertical axis).

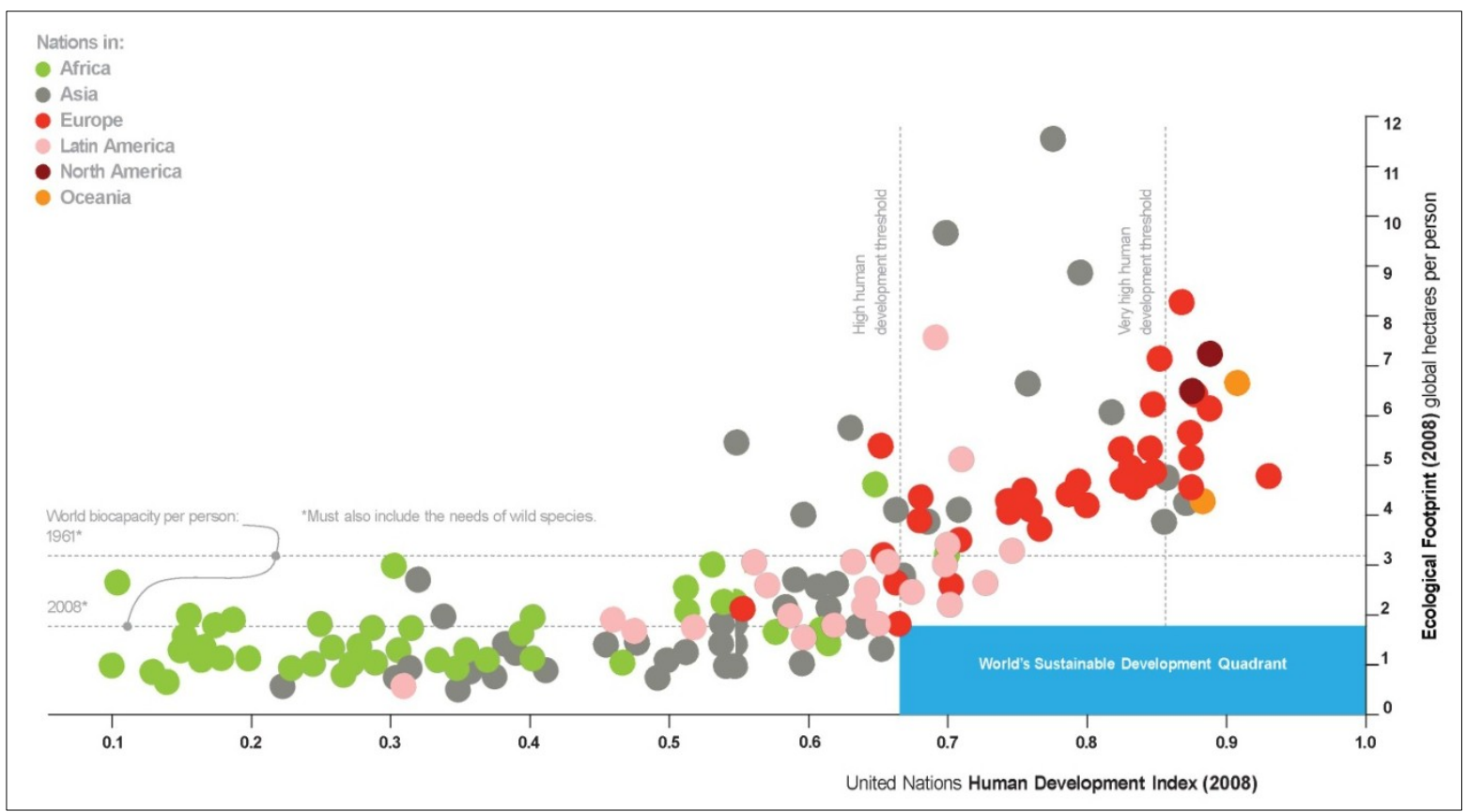

Source: Global Footprint Network [21]. 
This difference between developed and developing countries highlights three contentious aspects of SCP:

- Equity among populations and equal access to ecological resources to meet wellbeing needs;

- Fairness in the distribution of the burden and damages from historic and present unsustainable consumption and production;

- Differences in the capacities of developed and developing countries to address the problems of unsustainable consumption and production.

Addressing these three would go a long way toward easing the implementation of SCP objectives in the SDGs. Agenda 21 recommends "a multipronged strategy focusing on demand, meeting the basic needs of the poor, and reducing wastage and the use of finite resources in the production process" [1]. However, the current development paradigm is mainly based on the idea of "catching up", meaning that low-income countries are assumed to gradually approach the levels of wealth and material standard "enjoyed" by industrialized countries. The rich countries are basically assumed to continue on a business-as-usual track, getting increasingly affluent, while making efforts to "decouple". This idea might have been viable in the past, but this is no longer the case. On a crowded planet with a rapidly degrading resource base, the "catching up" model of development needs to be replaced with a new vision of "contraction and convergence". This vision is based on the following two principles:

(1) Reduced levels of consumption by developed countries. For the SDGs to be seen as applicable to all, industrialized countries need to, while ensuring the wellbeing of their citizens, commit to reducing their level of material consumption. This is as much desired as it is imperative in order to give the Post-2015 Development Agenda fairness and legitimacy.

(2) Increased quality of consumption by developing countries. Poverty is unsustainable; developing countries need to increase the level of consumption of low-income groups, especially of basic necessities, to at least meet minimum requirements for health and dignity, while adopting the most sustainable methods available to avoid causing the same levels of ecological harm as has been seen with developed countries.

The upshot of such an approach is that a reconciliation of SCP goals between developed and developing countries would eliminate extremes of poverty and material wealth and adopt new ways of producing and/or meeting needs in society that are less ecologically damaging.

It is, however, important to recognize that in all countries, even the least developed ones, exists an affluent elite enjoying material standards that exceed what is sustainable. The onus for reducing consumption levels cannot be placed only on advanced countries. Similar changes should be expected from the rapidly growing consumer class in the developed world. In order for the SDGs to be universal, goals and targets would have to reflect this reality.

\subsection{Towards a Monitoring Framework for SCP: General Principles}

As pointed out above, SCP is a broad agenda that is related with basically all economic sectors and many aspects of society. There have been a large number of efforts to formulate SCP indicators [8,22,23], attesting to how difficult it is to capture the breadth and complexity of SCP in just a few metrics. However, the SDG process would need to do just this: to establish a few headline indicators that 
capture the most essential elements of a transition to SCP. The intention in this paper is not to present a fully-fledged global SCP indicator framework for the SDGs; that is part of the SDGs negotiations process. How SCP indicators can be designed to effectively represent SCP objectives and trigger meaningful policy action depends on which of the two options discussed above is taken, as well as on how main goals and subsidiary goals in general are set. What we try to do in the following is to highlight some principles that could guide the formulation of indicators and to point out some concrete opportunities. At the general level, the SCP indicators used in the SDGs should be able to demonstrate two things: whether human impact on planet Earth is decreasing towards sustainable levels; and whether people's quality of life is improving. We elaborate these two points in the following sections.

\subsubsection{Ecological Sustainability}

The SDGs should reflect the need to protect the life-supporting environmental systems upon which human wellbeing ultimately depends. However, for the design of indicators in the context of the SDGs, it may not be feasible to try to monitor the state of all relevant environmental systems. A more feasible approach would be to focus on the key drivers of environmental degradation. One way of doing that is by measuring the ecological footprint per country and per capita. This approach is widely understood even outside of academic circles. Another, less widely known way is monitoring aggregate material consumption, an indicator that adds up a society's consumption of natural resources (mainly metals and ores, biomass, fossil fuels and construction minerals). There are now established methodologies and databases available for Material Flow Accounting (MFA) that make it possible to assess the resource consumption of individual nations [24]. Such an aggregated pressure indicator is not a perfect measure of environmental impact. This can be illustrated by the fact that a ton of mercury has the potential to cause more harm than a ton of sand, but the actual impact depends on how these materials are handled. However, the material consumption indicator has become widely accepted and is now being used by a number of countries, including the EU and Japan, as a strategic sustainability indicator. In addition, it is worth noticing that countries recently agreed on internationally harmonized standards for the System of Environmental-Economic Accounting (SEEA). The gradual implementation of this framework over the coming years will generate improved availability and quality of data. This will enhance countries' capacity to effectively monitor the state of the environment and to better understand the drivers of environmental degradation. These emerging opportunities need to be fully exploited when designing a global monitoring framework for sustainable development.

The MFA-based indicator discussed above has one major weakness as a metric for monitoring progress toward SCP. It accounts for material consumption based on where natural resources are extracted and used in production, not based on where products and services are consumed. While such information can be valuable, it fails to reflect the effects of international trade and globalization. With this accounting principle, countries that are outsourcing industrial production abroad will seem to be reducing their material consumption. However, if one considers the final consumption of goods and services as the driving factor of resource extraction and industrial production, it would make more sense to account for resource consumption based on where final consumption takes place. To capture this dynamic, there are now methods available for calculating such an indicator, the material footprint [25]. For many policy applications, this indicator provides more relevant information than indicators using 
production-based accounting. We therefore argue that consumption-based indicators should be seriously considered for inclusion in the monitoring framework for the SDGs.

Many policy applications of material consumption indicators are using metrics expressed in relative terms. Resource intensity (material consumption/GDP) is a commonly used metric. Such a relative indicator can convey something about the composition of a country's economy and the structural shifts that take place over time. However, it fails to show whether an economy's ecological pressure is actually increasing or decreasing. This observation is related to our discussion on the shortcomings of the decoupling approach in Section 3. As an indicator for monitoring progress towards SCP, we argue that absolute measures of resource consumption are preferable over relative decoupling (or efficiency) metrics.

\subsubsection{Social Sustainability}

The objective of SCP is not only to limit negative impacts on the Earth's life-supporting systems, but also to provide for human wellbeing within ecological limits and to promote equity.

- Wellbeing

Improved human wellbeing is at the heart of SCP, and the SDGs need to establish ways of monitoring whether human society is making progress towards this objective. In practice, GDP has often been used as a proxy for welfare and wellbeing, the logic being that when countries get richer, their citizens are better off. However, there is now a large body of research showing that the relationship between the level of economic activity and wellbeing is far from straightforward. Furthermore, in policy circles, there is now a growing recognition that GDP is not suitable as a wellbeing indicator, at least not in isolation. Responding to the calls for better indicators in this domain, studies in happiness and wellbeing are now a very active research area. These activities involve not only academic institutions, but also international organizations. The Organisation for Economic Co-operation and Development (OECD), for example, has developed its Better Life Index with a view toward providing a more multifaceted assessment of how well their member countries succeed in providing favorable conditions for human wellbeing. Several developed countries have recently developed, or are in the process of developing, accounting frameworks for quality of life or wellbeing. Bhutan's Gross National Happiness index is a developing country initiative that has drawn significant attention. There is thus a rapidly growing body of experiences for the SDGs process to draw from.

\section{- Equity}

Inequity can be regarded as unsustainable in its own right, but it can have negative implications for sustainability indirectly as well. High or increasing disparity in a society can easily trigger social tension and unrest, even open violence. Large gaps between rich and poor can also stimulate high levels of consumption of positional goods used to signal social status. Citizens in less unequal societies have been found to have less need for this type of consumption, since social status is reflected in other ways than through material consumption [10]. Although (in)equity has many dimensions, the most commonly used indicator is the Gini coefficient based on household income. We argue that social disparity is a key dimension of SCP that should be addressed in the SDGs. The Gini coefficient could be one strong candidate, since it is well established, and data availability is relatively good. 


\section{Discussion}

Shifting to SCP will require fundamental changes in the way society operates and how we live our lives. Such a full-scale transition will take considerable time; thus, given the urgency and magnitude of unsustainability and the central role of consumption and production, there is a need for immediate forceful action to bring the transition in motion. The SDGs, which are expected to be in place for a 15-year period starting from 2015, should serve as a catalyst to kick-start this societal transformation. This requires addressing the major drivers of consumerism and overconsumption, as well as unequal consumption opportunities, in modern society. Dealing only with the symptoms and addressing only the politically less challenging issues (the proverbial low-hanging fruits) will not result in the kind of changes needed for putting our civilization on the track to sustainability. The goals and indicators of the SDGs, and the associated action plans for implementation, must be formulated from this perspective.

Furthermore, SCP as reflected in the SDGs, must be coordinated with the 10YFP to ensure complementarity and synergies. An immediate opportunity for such coordination is through the 10YFP UN Inter-Agency Coordination Group. The setting of indicators and targets for both the SDGs and the 10YFP is a foundation for complementary operation. Together, both programs would need a comprehensive set of indicators that would consolidate environmental, social and economic elements into a common framework for monitoring progress. A periodic report as such would show: (a) how production and consumption patterns contribute or fail to contribute to the wellbeing of people; and (b) how the prospects of achieving wellbeing by future generations are threatened or safeguarded by current production and consumption activities.

\section{Conclusions}

The paper discussed the role of SCP in the SDGs and how SCP objectives could be effectively reflected in this emerging global policy framework. It argued that SCP, as a policy agenda for addressing the root causes of our ecological predicament, while at the same time providing for human wellbeing and prosperity, needs to be prominently featured in the SDGs. It observed that SCP has a key role to play in existing policy initiatives, for example on climate change, biodiversity protection and energy, and found that having SCP properly reflected in the SDGs could strengthen the attention given to the underlying drivers of these global issues. It discussed the pros and cons of two options: having SCP as a stand-alone SDG or as a cross-cutting objective embedded in other goals. It found that both options have significant advantages and disadvantages and concluded that a more critical issue than which of these two options is taken is how to establish sub-goals, indicators and targets in support of SCP objectives. In consequence, the paper provided recommendations towards the formulation of SCP-related indicators in the SDGs framework, including using aggregate material consumption (based on Material Flow Accounting) as a key pressure indicator, using indicators based on where final consumption takes place rather than where resource extraction and production happen (footprint-based indicators), using indicators formulated as absolute measures of consumption and ecological pressure, rather than intensity indicators, expressed relative to GDP, and including measures of human wellbeing despite the difficulties in defining a perfect indicator. 


\section{Acknowledgments}

The authors would like to thank Philip J. Vergragt (Tellus Institute, Boston), Eric Zusman and Mark Elder (Institute for Global Environmental Strategies (IGES), Hayama) for their comments on the paper. We also thank the anonymous reviewers, editors and the guest editors of this Special Issue for their guidance.

\section{Conflicts of Interest}

The authors declare no conflict of interest.

\section{References}

1. United Nations (UN). Agenda 21: Programme of Action for Sustainable Development; UN: New York, NY, USA, 1992.

2. United Nations (UN). Plan of Implementation of the World Summit on Sustainable Development; UN: New York, NY, USA, 2003.

3. United Nations (UN). The Future We Want; UN: New York, NY, USA, 2013.

4. United Nations (UN). A New Global Partnership: Eradicate Poverty And Transform Economies Through Sustainable Development; The Report of the High-Level Panel of Eminent Persons on the Post-2015 Development Agenda; UN: New York, NY, USA, 2013.

5. Stakeholder Forum. UNDESA Survey on the Sustainable Development Goals, Synthesis of responses from UN Member State Missions. Available online: http:/www.stakeholderforum.org/fileadmin/ files/Analysis\%20SDG\%20UNDESA\%20Survey_Final.pdf (accessed on 29 November 2013).

6. An Action Agenda for Sustainable Development: Report for the un secretary-general. Available online: $\quad$ http://unsdsn.org/files/2013/11/An-Action-Agenda-for-Sustainable-Development.pdf (accessed on 29 November 2013).

7. Advanced unedited copy: Progress report on the work of the General Assembly Open Working Group on SDGs at its first four sessions. Availale online: http://sustainabledevelopment.un.org/ content/documents/1927interimreport.pdf (accessed on 29 November 2013).

8. United Nations Environment Programme (UNEP). ABC of SCP: Clarifying Concepts on Sustainable Consumption and Production; UNEP: Paris, France, 2010.

9. United Nations Environment Programme (UNEP). Decoupling Natural Resource Use and Environmental Impacts from Economic Growth; UNEP: Paris, France, 2011.

10. Jackson, T. Prosperity Without Growth: Economics for a Finite Planet; Earthscan: New York, NY, USA, 2009.

11. Cohen, M.J.; Brown, H.S.; Vergragt, P.J. Innovations in Sustainable Consumption: New Economics, Socio-Technical Transitions, and Social Practices; Edward Elgar Pub.: Northampton, MA, USA, 2013.

12. Akenji, L. Consumer scapegoatism and limits to green consumerism. J. Clean Prod. 2014, 63, $13-23$.

13. United Nations Environment Programme (UNEP). Global Outlook on SCP Policies: Taking Action Together; UNEP: Paris, France, 2012. 
14. United Nations Environment Programme. TST Issue Brief: Sustainable Consumption and Production, including Chemicals and Waste; United Nations: New York, NY, USA, 2013. Available online: http://sustainabledevelopment.un.org/content/documents/2296SCP\%20Issues\% 20Brief\%20SDG_FINAL.pdf (accesses on 29 November 2013).

15. Griggs, D.; Stafford-Smith, M.; Gaffney, O.; Rockström, J.; Öhman, M.C.; Shyamsundar, P.; Steffen, W.; Glaser, G.; Kanie, N.; Noble, I. Sustainable development goals for people and planet. Nature 2013, 495, 305-307.

16. United Nations Environment Programme (UNEP). Embedding the Environment in Sustainable Development Goals: UNEP Post 2015 Discussion Paper 1; UNEP: Nairobi, Keyna, 2013.

17. Nair, C. Consumptionomics: Asia's Role in Reshaping Capitalism and Saving the Planet; Wiley: New York, NY, USA, 2011.

18. Website of the SCP 10-Year Framework of Programmes. Available online: http://www.unep.org/10yfp (accessed on 29 November 2013).

19. Akenji, L. Global Outlook on SCP policies: Asia-Pacific. In Global Outlook on Sustainable Consumption and Production Policies: Taking Action Together; United Nations Environment Programme (UNEP): Paris, France, 2012.

20. United Nations Environment Programme (UNEP). Sustainable Consumption and Production for Poverty Eradication; UNEP: Paris, France, 2012.

21. Global Footprint Network 2012. Available online: http://www.footprintnetwork.org/ images/article_uploads/2011_Annual_Report_RF.pdf (accessed on 29 November 2013).

22. Watson, D.; Lorenz, U.; Stenbæk Hansen, M.; Szlezak, J.; Zoboli, R.; Kuhndt, M.; Wilson, C.; Mont, O.; Wittmer, D. Towards a Set of Indicators on Sustainable Consumption and Production (SCP) for EEA Reporting; ETC/SCP working paper 1/2010; European Topic Centre on Sustainable Consumption and Production (ETC/SCP): Copenhagen, Danmark, 2010.

23. United Nations Environment Programme (UNEP). SCP Indicators for Developing Countries-A Guidance Framework; UNEP: Paris, France, 2007.

24. Economy-wide Material Flow Accounts (EW-MFA): Compilation Guide 2012. Available online: http://epp.eurostat.ec.europa.eu/portal/page/portal/environmental_accounts/documents/Economywide $\% 20$ material\%20flow\%20accounts\%20compilation\%20guide\%20\%20-.pdf (accessed on 29 November 2013).

25. Wiedmann, T.O.; Schandl, H.; Lenzen, M.; Moran, D.; Suh, S.; West, J.; Kanemoto, K. The material footprint of nations. Proc. Natl. Acad. Sci. USA 2013, doi: 10.1073/ pnas. 1220362110.

(C) 2014 by the authors; licensee MDPI, Basel, Switzerland. This article is an open access article distributed under the terms and conditions of the Creative Commons Attribution license (http://creativecommons.org/licenses/by/3.0/). 